\section{LANGUAGE LATERALIZATION AND UNILATERAL ECT}

Dear SiR,

Dr Allen's suggestion of applying Levy and Reid's method for determining cerebral lateralization of speech to the choice of hemisphere for unilateral ECT (Journal, March 1980, 136, 316) would seem premature.

Discrepant findings, Herron et al (1979) and McKeever and Van Deventer (1980) question the validity of the relationship between handwriting posture and cerebral localization of speech. In view of results such as these, it would be prudent not to incorporate this procedure into routine clinical practice, despite its attractiveness of speed and simplicity, until the relationship between hand posture and speech localization is further clarified.

Royal South Hants Hospital, E. Chan Pensley

Graham Road, Southampton SO9 4PE

\section{References}

Herron, J., Galin, D., Johnstone, J. \& Urnstein, R. E. (1979) Cerebral specialization, writing posture and motor control of writing in left handers. Science, 205, 1285-9.

McKeever, W. F. \& Van Deventer, A. D. (1980) Inverted handwriting position, language laterality and the Levy-Nagylaki genetic model of handedness and cerebral organization. Neuropsychologia, 18, 99102.

\section{LITHIUM AND PLATELETS}

Dear Sir,

The paper by Coppen et al (Journal, March 1980, 136, 235-238) provides interesting results but it is difficult to see that the declamatory title 'Lithium Restores Abnormal Platelet 5-HT Transport in Patients with Affective Disorders' is entirely justified.

The main cause for doubt is that results which are taken to demonstrate the effects of Lithium (e.g. $V \max =19.5$ in recovered depressives; $V \max =$ 27.8 with Lithium therapy-Table I) are similar in magnitude to the apparent variability of the results of measurements in comparable groups (e.g. Vmax in controls, Table $I=30.6$; Vmax in controls, Table II = 24.8). Several examples of this variability, which receives no attention in the discussion, are apparent, hence it is difficult to know whether any weight can be attached to the conclusions.

A second factor which obscures evaluation of the paper is that the groups of patients studied are not clearly defined. Though recovered depressives and Lithium-maintained patients are well described two other groups of patients on lithium are introduced without discussion of their characteristics.

\section{Littlemore Hospital, Littlemore, Oxford OX4 $4 X \mathcal{N}$ \\ THE DISABILITIES OF GHRONIC SGHIZOPHRENIA}

DeAr SiR,

E. Crouar

Drs Cunningham Owens and Johnstone in their article on the disabilities of chronic schizophrenia (Journal, April 1980, 136, 384-395) confirmed clinical impressions that the deficits are multiple. It was unjustified, however, to comment that ". . . these deficits result from a disease process and are unlikely to be cured by rehabilitative measures". The article made no reference whatever to whether these patients have had rehabilitative treatment or not and the authors simply, with a single stroke, brushed away any possible benefit from rehabilitation. It is interesting to note that their own earlier study had shown that social and behavioural performance need not necessarily be related to the features of the mental state. Rehabilitation aims to improve social and behavioural performance and never to 'cure'.

L. Y. Cheno

Department of Psychiatry, Joan Cristoveanu

Queen's University and

Kingston Psychiatric Hospital,

Kingston, Ontario, Canada

\section{Reference}

Johnstone, E. C., Frith, C. D., Gold, A. \& Stevens, M. (1979) Outcome of severe acute schizophrenic illnesses after one year. British Fournal of Psychiatry, 134, 28-33.

\section{SCHIZOPHRENIA: THE EFFECT OF TELLING THE PATIENT AND RELATIVES}

DEAR SiR,

I have avoided for many years giving a diagnosis of schizophrenia to patients and their relatives. I have used, perhaps naively, 'depression' or 'anxiety' with emphasis on the normal aspects of the individual and the potential for rehabilitation. It was, therefore, with relief and satisfaction that I read Professor Ciompi's article in this fournal (May 1980, 136, 413-20) confirming that schizophrenia is a nonentity as a diagnosis and has no significant therapeutic or prognostic value. I wonder how many practising psychiatrists have felt the same way.

I believe a diagnosis of schizophrenia, which in the lay mind is no less devastating than that of multiple sclerosis, could inflict a lot of avoidable 